\title{
Propuestas de reforma en salud y equidad en Uruguay: ¿redefinición del Welfare State?
}

\author{
Proposals for health reform and equity in Uruguay: \\ a redefinition of the Welfare State?
}

Myriam Mitjavila 1

José Fernández 1

Constanza Moreira 1

1 Centro de Informaciones y Estudios del Uruguay. Maldonado 1858, 11200, Montevideo, Uruguay. ciesu@chasque.apc.org
Abstract This article reviews and analyzes health sector reform proposals in Uruguay and the possible effects of such reforms in terms of equity, the health sector's institutional structure, and the power relationship between the various actors in the process. The authors contend that a highly structured yet si multaneousl y fragmented system has conspi red against any attempt to introduce maj or reforms into the system. Thus the only possi bility for reform resi des neither in the consolidation of the so-called Institutions for Collective Medical Care (IAMCS) nor in the movetowards a residual model. Rather, U ruguay is witnessing the system's passive restructuring (i.e., reform by default). In this context and given the system's built-in inequities, the current trend is towards an even more regressive distribution of goods and services. The authors use qualitative and quantitative techniques to show that inequities in expenditure, access, and quality have resulted from long-term developments and adaptive movements of an IAMC system in fiscal stress and the public system's declining quality. Thus, in the absence of changes in state policy that redefine the actors' power or in the absence of system collapse, the country should expect this same regressi ve trend to deepen.

Key words Equity; Heal th Sector Reform; Health System; Health Care Reform

Resumen En el presenteartículo se realizan una revisión y un análisis de las propuestas de reforma del sector Salud en Uruguay, y de los posi bles efectos de estas reformas en términos de equidad, estructura institucional del sector y relaciones de poder entre los actores invol ucrados en el proceso. Encontramos que las características contradictorias del sistema de salud, por un lado altamente estructurado y, al mismo tiempo, fragmentado, conspi ran contra los esfuerzos reformistas que intentan introducir cambios en el mismo. En función de lo expresado, las posibilidades de reforma no residen en la consolidación de las IAMC (Instituciones de Asistencia Médica Colectiva) ni en la aplicación del modelo residual. Por el contrario, asistimos a un proceso de reestructuración pasi va del sistema. En este contexto, y teniendo en cuenta el nivel de inequidades existentes, la tendencia que se percibe es de profundización de una distribución regresiva de benefi ci os y servicios. A partir de técni cas cualitativas y cuantitativas, mostramos como las inequi dades relacionadas con el gasto, el acceso y la cal idad están relacionadas con procesos de desarrollo de largo ti empo del sistema IAMC y con los movimientos adaptativos frentes a su colapso fiscal, por una parte, y con la pérdida de calidad del sistema público, por otra.

Palabras clave Equidad; Reforma del Sector Salud; Sistema de Salud; Reforma en Atención de la Salud 


\section{Introducción}

La crisis económica y las reformas estructurales iniciadas en los años 80 en América Latina han implicado altos costos sociales, así como cambios sustanciales en los patrones de desarrollo e integración social prevalecientes. En el caso uruguayo, puede apreciarse que la reforma del Estado se ha desarrollado de manera atípica, cuando se la compara con otros países de la región. La forma de resolver la tensión entre las reformas orientadas al mercado y los programas de Social Welfareha derivado en un modelo de reforma "desobediente" a las tendencias marcadas por los organismos internacionales.

La dificultad para desmantelar el modelo de Estado benefactor en un contexto democrático ha inducido procesos graduales de reforma (alto respeto por el timing), con fuertes contenidos estatistas, y altos niveles de negociación con los agentes (identificación de coaliciones de veto y lobbys de veto) (Filgueira et al., 1999). Una simple mirada comparativa muestra la consistencia del esfuerzo social: Ios indicadores sociales evidencian la mejor performance de Uruguay en relación a sus pares latinoamericanos, toda vez que la pobreza urbana disminuyó del $11 \%$ al $6 \%$ en los años 1981-1994, y el coeficiente de Gini pasó de 0,39 a 0,30 en el mismo período (CEPAL, 1997). El coeficiente de Gini se utiliza en este caso para medir concentración del ingreso. Se calcula en base al ingreso promedio en los hogares y varía entre 0 y 1. Cuanto más cercano a 1, mayor concentración del ingreso.

En la investigación que dio origen al presente artículo, se utilizó el concepto de equidad para analizar las desigualdades en la atención a la salud, focalizando la evaluación de los impactos de las políticas sociales y, particularmente, de las medidas de reforma adoptadas en el sistema de salud, sobre los niveles y formas de las desigualdades preexistentes. Desde esa perspectiva, en el marco de nuestro trabajo, entendemos que las inequidades están asociadas a desigualdades consideradas socialmente injustas (Whitehead, 1992). Los valores de equidad se asocian en Uruguay a la persistencia del WelfareState, en un marco donde las tendencias al desmantelamiento del mismo, en función de un modelo de Estado Liberal Social, son fuertes. En el sub-sector privado, la persistencia del Welfare State se manifiesta en medidas de subvención estatal al sub-sector, asegurando una cobertura con canasta universal, generando un tipo de seguro que, al no cobrar cuotas ajustadas por riesgo, se transforma en un híbrido entre la modalidad de seguro priva- do y la de seguridad social. En el sub-sector público, el Welfare State está presente en los principios universalistas de la cobertura, cuestionados por la tendencia hacia políticas residuales que intentan focalizar el servicio sobre la población indigente.

La cuestión de la equidad en salud necesariamente debemos inscribirla en el marco de una discusión más amplia, o sea, en el marco de los costos del desmantelamiento del Welfare State en países de ingresos medios como Uruguay. Como bien señala Nelson (1992), los nuevos programas focalizados de ayuda (asociados en parte al modelo residual) pueden potencialmente ser de gran beneficio para aquellos países que cuentan con índices significativos de población en situación de pobreza extrema. Sin embargo, para las naciones de ingresos medios y con cierta institucionalización de los sistemas de seguridad social (como en el caso uruguayo), la direccionalidad del modelo sustituto en el sistema de salud podría tener un impacto social negativo en términos de equidad, en la medida que los sectores supuestamente beneficiarios son relativamente pequeños en relación a los trabajadores formales, estratos semi-pobres y medios que dejan de contar con el amparo de los programas sociales. De esta manera, los países de ingresos medios pueden verse sometidos a la generación de formas de desigualdad social antes desconocidas. Si bien la teoría económica y las experiencias de liberalización del mercado tienden a sugerir que estas pérdidas son transicionales, y en el futuro inmediato la propia dinámica del crecimiento las revertirá, los grupos "perdedores" tienden a resistirse con más o menos fuerza a pagar dichos costos (Bresser et al., 1993).

Del mismo modo que no existió un tipo universal y extensible de WelfareState, el denominado modelo residual (Midaglia, 1998) deberá contemplar las diferencias contextuales. Siendo así, el sistema de salud en el Uruguay es un sistema altamente institucionalizado, históricamente consolidado y bastante complejo. Su estructura y funcionamiento son bastante diferentes de los otros países de la región, en gran medida por las características específicas de la estructura poblacional y por los problemas de salud inherentes a ella, como también por la historia misma de estructuración del propio sistema de servicios de salud. Al mismo tiempo, y de manera también diferenciada en el contexto latinoamericano, el Estado uruguayo no se transformó en el principal proveedor de servicios de salud, si bien cubre a un promedio del $40 \%$ de la población, con mayor impacto en el interior del país, en relación a la capital, Mon- 
tevideo. Esto obedece a que, en la segunda mitad del siglo $X X$, se encontraban ya consolidadas las Instituciones de Asistencia Médica Colectiva (IAMC) en Uruguay, creadas originalmente por inmigrantes; luego fueron expandiendo sus servicios a la población en general, transformándose en actores privilegiados del sistema de seguros de salud.

La Seguridad Social al canza una cobertura relativamente baja en su seguro de salud (16,6\% de la población total y $30 \%$ de la población activa). Este seguro cubre a los trabajadores de la actividad privada en forma obligatoria y presta sus servicios exclusivamente a través de las IAMC. Se financia con aportes empresariales, más un porcentaje del salario de cada trabajador. El Banco de Previsión Social (BPS) recauda estos fondos y los asigna a las I AMC efectoras del servicio. Este seguro cubre por, otra parte, las licencias por enfermedad, pensiones y otros gastos derivados de las enfermedades profesionales. La cobertura alcanza solamente a los trabajadores formales activos o en seguro de desempleo, quedando excluídas sus familias, y a los jubilados de menores ingresos. La Seguridad Social cubre, por otra parte, la atención materno-infantil de la población que no tiene acceso a la cobertura de las IAMC.

Por otro lado, en Uruguay, el Banco Mundial jugó un rol central en la definición de las propuestas de reformas, y todas las medidas por él propuestas - contención de costos y gastos, disminución de la provisión pública, aumento de la eficiencia, descentralización, introducción de competencia, privatización y aumento de la capacidad reguladora del Estado- están contempladas en la propuesta del proyecto de Fortalecimiento Institucional del Sector Salud (FISS), financiado por el propio Banco Mundial. Pero, en un sistema altamente consolidado, institucionalizado y complejo como el uruguayo, la "traducción" de estas medidas sólo es posible en forma parcial y limitada, e incluso contradictoria: la recuperación de costos en el sistema público y la descentralización y autonomía hospitalaria van de la mano con la idea de que éstas puedan transformarse en instituciones competitivas en un mercado "abierto" de servicios de salud. A su vez, el aumento de la capacidad reguladora del Estado implica la creación de figuras públicas no estatales para elaborar las grandes directrices en materia de salud, al tiempo que la "liberalización" de la competencia entre efectores encuentra en las I AMC un escenario de resistencias importantes.

El presente artículo tiene por objetivo presentar los principales resultados de una inves- tigación dirigida a relevar y examinar las propuestas de reforma del sector salud en Uruguay, así como sus eventuales impactos sobre las desigualdades sectoriales en términos de equidad, su consistencia con las estructuras institucionales y las relaciones de poder prevalecientes entre los principales actores.

La hipótesis que guió la investigación sostiene que existen dos estrategias contradictorias entre los agentes vinculados a la élite del sistema: (a) una que procura consolidar el modelo representado en las IAMC, como paradigma inspirado en la versión uruguaya del welfarey, por lo tanto, de políticas integradas en el área; (b) y otra orientada a la instrumentación del modelo residual. Este tipo de modelo se apoya fuertemente en la focalización política del problema de la pobreza para la provisión selectiva de los servicios de salud y en la redefinición del papel del Estado como proveedor. En este último aspecto, se trabajó con la hipótesis de que las estrategias inspiradas en el modelo residual tienen efectos regresivos sobre los parámetros de equidad vigentes en el actual sistema de salud.

\section{Metodología}

Esta investigación requirió un diseño complejo, que complementa la metodología cualitativa, propia de la evaluación de políticas, con un estudio exploratorio sobre estrategias y procedimientos de reforma. Se complementa esta estrategia con una triangulación de técnicas, donde se integran elementos de análisis cuantitativo para el relevamiento de indicadores proxi de equidad.

Para analizar el proceso gradual de reforma, se ha optado por identificar hitos relevantes, conceptualizados como momentos del proceso donde se producen cambios cualitativos en los elementos clave que lo componen (Moreira \& Fernández, 1997), identificándose seis hitos relevantes.

Combínase al mismo tiempo: (a) recolección de información primaria (técnicas cualitativas de entrevistas en profundidad), (b) análisis de documentos, y (c) análisis estadístico de informaciones de tipo secundario (cobertura, financiamiento y gasto). El análisis fue específicamente político, articulándose las informaciones cuali y cuantitativas.

Para estudiar los agentes colectivos, se empleó una estrategia comprensiva, que abarca al agente, su contexto institucional y las redes que integra. La muestra fue intencional e incluyó a la tecno-burocracia estatal, consultores 
de organismos bilaterales, actores del sistema político, de corporaciones y del espacio académico. Las unidades de observación están constituídas por el discurso de los agentes.

La recopilación y la sistematización de la información asistencial se diferencian según los dos grandes sub-sectores, público y privado. En lo referente a gasto en salud, se han tomado las últimas cifras disponibles, correspondientes a 1995.

Partimos de la premisa que existen desigualdades entre las actuaciones de los dos subsectores y anal izamos los datos de gasto y cobertura de ambos. Para los efectos de ese estudio, la equidad entre usuarios está referida a la relación entre servicios brindados y nivel de gasto, y la equidad entre sub-sectores se refiere a los diferenciales de acceso y tipo de servicios según institución que brinde la cobertura.

En lo que toca a la cobertura, fue agrupada en dos valores - IAM C y no IAMC -, calculándose la tasa de cobertura IAMC desagregada por departamento y midiéndose la correlación existente entre esta tasa y algunos indicadores macro de desigualdad social, que en nuestro marco de análisis asociamos a inequidades. Fueron utilizadas dos fuentes para analizar cobertura, la Encuesta Continua de Hogares y el Censo de 1996, realizados ambos por el Instituto Nacional de Estadística (INE). Sin embargo, por la naturaleza de ambas fuentes, existe una diferencia sustancial en la población que se registra sin cobertura, la cual puede explicarse a partir de diversos factores: por un lado, el carácter del relevamiento de cada uno, ya que el primer caso se trata de una encuesta por muestreo y, en el otro, de un censo; por otro lado, en el primero se relevan datos de población urba- na, en el segundo se incluye población urbana y rural. A su vez, el tipo de pregunta que se realiza en cada caso puede estar afectando la medición de la población respectiva. Optamos entonces por trabajar con el Censo de 1996, desagregando la información por unidades territoriales. Los indicadores utilizados, y las respectivas fuentes estan en Tabla 1.

Para el análisis de la correlación de las variables individuales, tales como, edad y condición de actividad del individuo sobre el nivel de cobertura alcanzado, la fuente utilizada fue la Encuesta Continua de Hogares, por las limitantes planteadas en relación a los datos censales.

\section{Presentación de resultados}

El contexto reformista

Las políticas de desarrollo en el Uruguay de los últimos treinta años han experimentado un viraje profundo. Crecientemente, se ha ido aceptando la idea de que el viejo modelo “Estadodirigista" ya no era más sostenibley debería ser reemplazado. La fórmula de "economías en transición" sirvió para designar estas reformas orientadas al mercado que comenzaron a ponerse en práctica en la década del 70 , con lo que se dio en llamar la "primera generación de reformas". Uruguay ha comenzado a procesar, con posterioridad a la transición democrática, sus reformas de "segunda generación" o institucionales: Ia reforma de la Seguridad Social, de la Educación, de la Gestión Administrativa del Estado, y de la Salud, entre otras. Por otra parte, el proceso de reformas ha sido lento y

Tabla 1

Fuentes y formas de cálculo de los indicadores proxy de equidad.

\begin{tabular}{llll}
\hline Indicador & Fuente & Cálculo & Año \\
\hline Cobertura IAMC & INE (1996) & Porcentaje sobre el total departamental & 1996 \\
Cobertura no IAMC & INE (1996) & Porcentaje sobre el total departamental & 1996 \\
Tasa de cobertura IAMC & INE (1996) & Cociente entre cobertura IAMC y no IAMC & 1996 \\
Precarización del empleo & PNUD (1999) & Porcentaje de empleo precario sobre total de empleo & 1996 \\
IDH & PNUD (1999) & Índice integrado por: PIB per capita, Ingreso & 1996 \\
PIB departamental per capita & PNUD (1999) & En miles de dólares \\
PIB total. & PNUD (1999) & $\begin{array}{l}\text { Porcentaje de participación departamental en } \\
\text { el PIB total del país }\end{array}$
\end{tabular}

IAMC = Instituciones de Asistencia Médica Colectiva; INE = Instituto N acional de Estadística; IDH = Índice

de Desarrollo Humano; PIB = Producto Interior Bruto; PNUD = Programa de las Naciones Unidas para el Desarrollo. 
gradual, y ha experimentado muchos bloqueos desde la transición democrática.

El tránsito de las reformas de "primera generación" parece hoy completo. Según los estudios de Morley et al. (1999), Uruguay aparece no sólo como uno de los países más tempranamente reformado (junto con Chile y Colombia), sino como el país más reformado, en una lista de 17 países de América Latina.

Sin embargo, los estudios tienden a resaltar que la reforma del Estado en Uruguay se ha desarrollado en forma atípica cuando se le compara con otros países de la Región, en particular por la combinación de: (a) componentes "estatistas" importantes en todas las reformas; (b) prácticas gradualistas de introducción de las reformas.

Como ejemplo del componente "estatista" (o el predominio de soluciones "mixtas") pueden destacarse la reforma de la seguridad social y la reforma educativa, implementadas en el último ejercicio de gobierno. Como ejemplo de "gradualismo", en cambio, puede destacarse la reforma del sistema de salud: en su defecto, vista como una reforma "trunca", y en su versión más optimista, como una reforma "gradualista".

El carácter de la reforma, "desobediente" a las tendencias marcadas por los organismos internacionales, ha llevado a una relativamente buena performance social frente a la situación de Latinoamérica. Esta performancesocial no sólo está relacionada con las políticas sociales y la forma en que fueron reformadas,.sino que también se debe a que el régimen de Welfare State subsiste, de manera casi intacta, en algunos de sus contenidos básicos para las políticas de empleo, los derechos laborales, Ios convenios colectivos y los seguros de salud. Este tipo de orientación parece contribuir decisivamente al mantenimiento de un alto perfil respecto a indicadores sensibles en materia de desarrollo social. Lo mismo puede decirse respecto al gasto social público en general, y al gasto en salud, en particular. Los datos disponibles informan un crecimiento del gasto social y de salud. Entre 1984 y 1994, el gasto social público en Uruguay creció 165\%, representando un aumento de $130 \%$ como porcentaje del Producto Interior Bruto (PIB). En el mismo período, el gasto total en salud aumentó en 230\%, y $170 \%$ como porcentaje del PIB (PNUD, 1999), situación incompatible con las hipótesis que suelen predecir impactos regresivos de las reformas sobre el gasto público social. Por el contrario, en el caso uruguayo se alcanza a percibir un aumento significativo del gasto en salud, cuestión que se encuentra en el centro de la discusión que pretendemos dar sobre la reforma en este sector.

El sistema de salud

El sistema de salud en Uruguay es en buena medida responsable por la marcha de su reforma: es un sistema altamente institucionalizado, consolidado y complejo. Su formación es atípica en el continente, dada la transición demográfica y epidemiológica que el país conoció en las primeras décadas del siglo y que le obligaron a enfrentar problemas de salud no habituales para el resto de las poblaciones de América Latina. Uruguay se caracterizó por una transición demográfica temprana en el continente, que le permitió exhibir, ya en la primera década del siglo, niveles de mortalidad y tasas de fecundidad similares a los experimentados por las poblaciones de los países industrializados. Entre 1880 y 1940, el país redujo en 60\% la natalidad. Como consecuencia de estas tendencias, Uruguay exhibe una estructura de población relativamente envejecida y un bajo crecimiento vegetativo. En 1963, los menores de 15 años representaban el $28 \%$ de la población mientras que, en 1985 , eran $26 \%$ y en 1996 , el $25,2 \%$. Los mayores de 64 años casi se duplicaron en número, pasando del $8 \%$ al $15,7 \%$ de la población total en 1985, bajando al $13 \%$ en 1996. La tasa global de fecundidad es de 2,3 (INE, 1963; 1985; 1996). Entre las causales aducidas para dar cuenta del fenómeno, se cuentan: Ia temprana incorporación de la mujer al mercado de trabajo, la rápida urbanización y expulsión de las poblaciones rurales (caracterizadas por altos niveles de fecundidad), así como la "modernización" de actitudes y comportamientos, fruto de la temprana industrialización del país, de los procesos de expansión educativa que comenzaron en el siglo XIX y se extienden a la población femenina, y del peso relativamente menor de la Iglesia como agente de socialización cultural (CELADE/FNUAP/MSP/ OPS, 1994).

Las características demográficas del país, sumadas a una alta tasa de alfabetización (sólo $3,1 \%$ de analfabetos), a la extensión de la red de agua potable ( $80 \%$ de las viviendas conectadas a la red general) y a buenas condiciones de evacuación del servicio (sólo 4\% de las viviendas sin sistema de evacuación del servicio sanitario y sólo $4 \%$ de viviendas sin sistema de eliminación de excretas) explican el predominio de las enfermedades crónicas sobre las patologías infecciosas como causa de muerte. Por lo tanto, aunque Uruguay es un país pequeño $\left(176.215 \mathrm{~km}^{2}, 3.322 .141\right.$ habitantes y una densi- 
dad de 18,8 habitantes/ km²), en desarrollo y de medianos ingresos, presenta características demográficas comparables a las de los países desarrollados: un 87,3\% de su población está radicada en áreas urbanas siendo casi el 50\% en Montevideo, la esperanza de vida al nacer para el hombre (48\% de la población) es de 69,3 años de vida y para la mujer (52\% de la población) de 75,5; la tasa bruta de natalidad por mil habitantes es de 16,3 y la tasa anual de crecimiento es de $0,68 \%$. En cuanto a la mortalidad, las causas de muerte corresponden en $38,7 \%$ a enfermedades del aparato circulatorio, $22,7 \%$ a tumores malignos, $4,9 \%$ a accidentes y $2,1 \%$ a diabetes mellitus.

A diferencia del resto de los países de América Latina, en el cual el Estado se transformó en el principal proveedor de servicios de salud, en Uruguay las IAMC son los principales efectores del sistema. Al mismo tiempo, el rol del Estado como prestador de servicios es ineludible, al menos en el corto plazo. El sector público cubre al $40 \%$ de la población, incluyendo por mandato constitucional la atención gratuita a la población indigente y con aranceles progresivos de acuerdo al nivel de ingresos del usuario.

Por un lado, el sub-sector privado, mediante las sociedades de asistencia (propiedad de médicos, o propiedad de usuarios), cubre los estratos medios y medios-altos, con capacidad de pago. Por otro lado, el sub-sector público se orientó principalmente a la prestación de servicios a aquellos estratos de población que no podían pagar los costos de las IAMC, configurando un modelo de atención que, sobre todo en la capital (Montevideo), se caracterizó por tener como eje central a los "hospitales para pobres". Entre 1960 y 1980, acuerdos bilaterales entre organismos estatales y las I AMC ampliaron la cobertura a todas los trabajadores formales del sector público y privado, resultando en un subsidio cada vez mayor del Estado al sistema IAMC.

El sub-sector público incluye el Ministerio de Salud Pública (MSP) y la Administración de Servicios de Salud del Estado (ASSE), la Dirección Nacional de Sanidad de las Fuerzas Armadas (DNSFFAA), la Dirección Nacional de Sanidad Policial (DNSP), el Hospital de Clínicas de la Universidad de la República (HC), las diversas Comisiones Honorarias que funcionan en el país (Lucha contra el Cáncer, Salud Cardiovascular, Lucha contra la Hidatidosis, Lucha Antituberculosa, etc.), el Banco de Previsión Social (BPS), el Banco de Seguros del Estado (BSE), la Intendencia Municipal de Montevideo (IMM), y otros efectores públicos de menor tamaño.
El sub-sector privado incluye a las IAMC, un conjunto de Seguros Privados totales y parciales (emergencias médicas, odontológicas, etc.), farmacias (gasto de bolsillo), casas de salud, y otras entidades de menor importancia. Asimismo, se separa en la clasificación tradicional al Fondo Nacional de Recursos (FNR), como seguro nacional para la cobertura de prestaciones caracterizadas como de medicina altamente especializadas y de alto costo, al cual concurre tanto población cubierta por efectores públicos como privados, con financiamiento proveniente de ambas fuentes.

Las IAMC son instituciones privadas; son los efectores de un mix de seguros de salud privados y públicos articulados a la seguridad social. Mediante un mecanismo de pre-pago, con cuota per capita y universal (no hay diferencias de cuota por riesgo), se asegura una cobertura con una canasta de prestaciones universal garantizada por el Estado. Se accede a las mismas por (a) pago de cuotas individuales, (b) cobertura del seguro de la seguridad social, y (c) por subsidios que el Estado otorga a parte de sus funcionarios para el pago de la cuota.

Como consecuencia, el sistema de salud uruguayo es constituído por un complejo mix público y privado, siendo que las IAMC juegan un importante papel como actores del sistema de seguros de salud.

El grupo de usuarios cubierto por el seguro salud de la seguridad social se constituye en un insumo clave para el equilibrio económico financiero de las instituciones. Si bien la cuota mensual que fija el Estado en este caso sea inferior al de una afiliación individual, se trata de un usuario cautivo, ya que el seguro es obligatorio, con ningún riesgo en el cobro de la mensualidad, porque la misma es descontada del salario del trabajador o de la jubilación, y se transfiere a las IAMC en forma centralizada. Un indicador de la importancia estratégica de las IAM C para el sostenimiento del sistema de salud es su participación en el gasto en salud en Uruguay, alrededor de $49,6 \%$ del gasto total y $69,4 \%$ del gasto privado.

En el decenio de 1980, aparece un nuevo actor privado: Ios seguros parciales de asistencia. Esta nueva modalidad de atención privada ya no responde a los cánones tradicionales del sector privado representado por las IAM C y, si bien inicialmente se restringió a la prestación de servicios (como las emergencias móviles) "descuidados" por las IAMC, con el tiempo su oferta se extendió, alcanzando una cobertura muy amplia.

Con relación al financiamiento del sector, importa señalar que la estructura de fuentes y 
usos de fondos es bastante compleja (Figura 1), a partir de la forma de contribución de las familias, de la canalización de los recursos en el sistema, y de cómo llegan a los proveedores. Por otro lado, la estructura de financiamiento está constituída por 3 modalidades básicas: pública, mixta y privada, con importantes interrelaciones entre ellas.

En el sector público, se presentan 3 modalidades diferentes: impuestos, proventos (venta de servicios de organismos del Estado) y precios. En el caso de la atención materno-infantil en el interior del país, los fondos se ejecutan a través de una articulación de organizaciones, el sub-sistema IAM C - Federación Médica del Interior (FEMI). En el caso de Ministerios y de Entes Autónomos, se paga el valor equivalente a la cuota de un seguro de pre-pago de una IAMC a algunos funcionarios, lo que implica un complemento salarial, ya que se entrega una partida de dinero con esta finalidad. Esta aplicación de fondos públicos provenientes de impuestos a la prestación de servicios privados no es universal para todos los funcionarios públicos, lo que se constituye en una fuente de desigualdad. En la medida que este aporte en "especie" no discrimina por ingresos, sino por institución a que pertenece el funcionario, se transforma en un mecanismo redistributivo a favor de ciertos sectores del Estado que están en una relación de "privilegio" en relación a otros. Si bien este mecanismo favorece a funcionarios de menores ingresos, también favorece a los de mayores ingresos que pueden financiar su cobertura en forma privada pero usufructúan este subsidio en igualdad de condiciones que los de menores ingresos, por lo que supone un efecto regresivo en términos de equidad. Es claro que el financiamiento del sector público no es homogéneo; las partidas para el MSP por usuario son significativamente menores que las que se aplican en las otras entidades del sector.

El sector mixto se basa en la modalidad de cuota, sea por afiliación privada o por seguro. Tiene un componente de financiamiento a través de impuestos en el Fondo Nacional de Recursos que aparte recibe un porcentaje de cada sub-sector. Lo que no está contabilizado en el sector mixto es el financiamiento indirecto, generado por exoneraciones fiscales a las I AMC, créditos blandos para salir de situaciones de crisis, moratoria de deudas con el Estado, etc.

El sector privado tiene un financiamiento que se reparte entre modalidades de pre-pago y pago directo de servicios.

En 1995 el sub-sector público participaba del $28,6 \%$ del gasto total en salud, mientras que el sub-sector privado gastaba el $71,4 \%$ restante. Esto muestra el peso relativo del sub-sector privado en la atención de salud en Uruguay, y la imposibilidad de diseñar políticas de salud sin tener en cuenta su participación. El 88\% de los recursos del sub-sector público proviene de impuestos, y sólo un $12 \%$ se distribuye entre diferentes modalidades de recuperación de costos. Este es uno de los elementos que constituye un aspecto central de la agenda de reforma, debido a que se asume en al gunos diagnósticos que los usuarios del sistema público tienen una capacidad de pago que no es captada por el sub-sector. En el sub-sector privado, el 59\% proviene del pago de cuotas (pre-pago) en diferentes modalidades. El restante $41 \%$ proviene del pago directo (gastos de bolsillo).

Para el caso de las IAM C, la disminución de la participación de la cuota y el aumento de los co-pagos por los usuarios fueron la tendencia en el período 1991-97 (SINADI, 1997). Este es un elemento clave en el análisis de la crisis del sub-sector. La cuota está regulada por el Ministerio de Economía y Finanzas (MEF), por tratarse de una variable de ajuste clave para controlar la inflación. Los co-pagos se instituyeron como mecanismo para desestimular el uso y controlar el consumo, pero, con el correr de tiempo, se han transformado en un impuesto directo al usuario enfermo, lo que desvirtúa en parte el contenido solidario y universal del sistema. De todas formas, la cuota continúa siendo la fuente fundamental de financiamiento, y las propuestas de reforma giran alrededor de mecanismos de fijación de la misma.

\section{El proceso de reforma en el sector salud}

Si consideramos el proceso de reforma del sistema de salud desde la post-transición democrática hasta el presente, se pueden vislumbrar seis momentos diferenciados (Moreira \& Fernández, 1997). Un primer momento se verifica en los acuerdos de la Concertación Nacional Programática para provocar la apertura democrática y canalizar los esfuerzos de cara a la instalación de un gobierno legítimo en 1985. Un segundo momento se identifica en ocasión de concretarse el proyecto de desconcentración de la atención de salud en el MSP con la ley de creación de la ASSE. en 1987, lo que implica un paso importante en dirección al principio de separación de las funciones asistenciales y normatizadoras del Estado (Piotti, 1995). Un tercer momento lo constituye la presentación de la Ley de Descentralización de la ASSE por parte del ministro Alfredo Solari en el marco de la Ley de Presupuesto de 1995, que 
Figura 1

Estructura de financiamento del sector salud.

Fuente

Ingresos de las familias
Sector principio

Público

Modo Financiamento

Entidad: recauda o canaliza

Efector

Impuestos
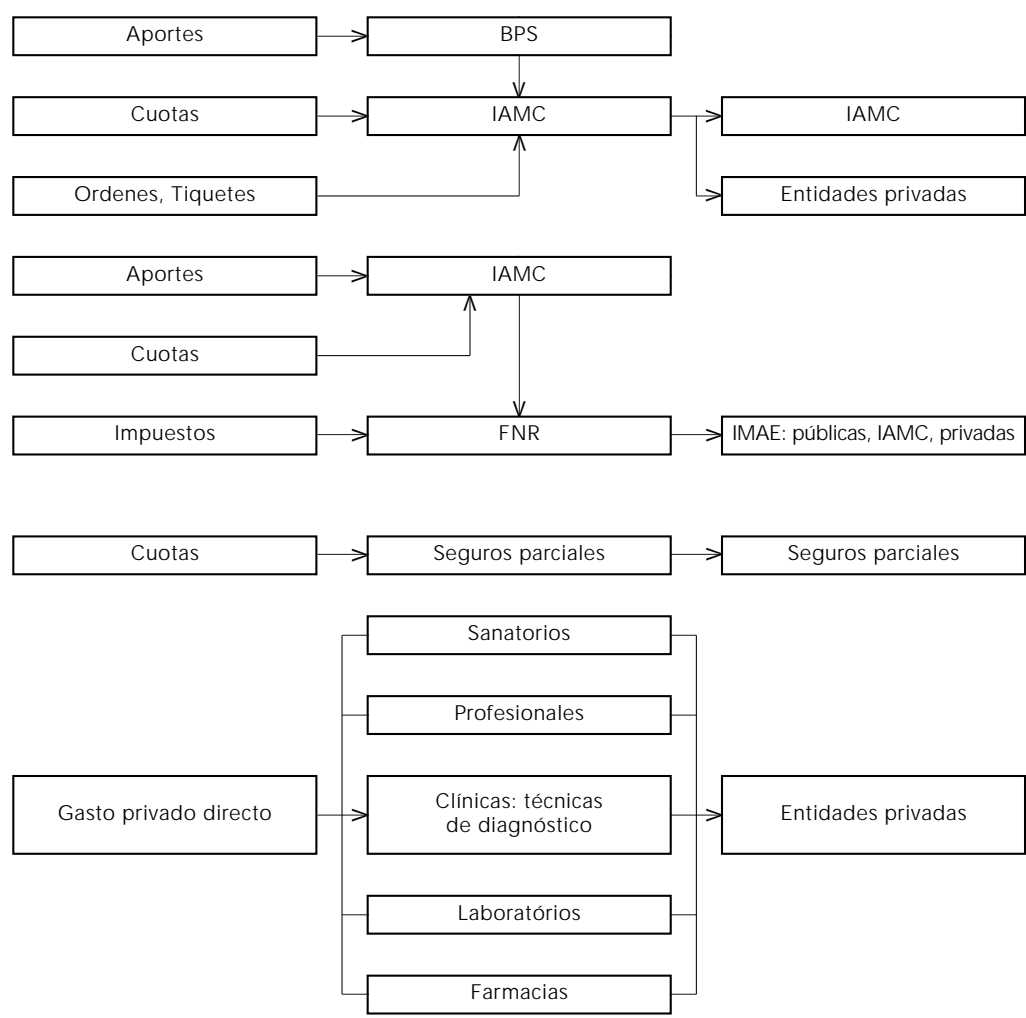

Elaboración propia. Centro de Informaciones y Estudios del Uruguay, 1999.

MSP = Ministerio de Salud Pública; BPS = Banco de Previsión Social; FF. AA. = Fuerzas Armadas; IAMC = Instituciones

de Asistencia Médica Colectiva; $B H U$ = Banco Hipotecario del Uruguay; BSE = Banco de Seguros del Estado;

IMAE = Instituciones de Medicina Altamente Especializada; FNR = Fondo Nacional de Recursos;

Ancap = Administración Nacional de Combustibles, Alcohol y Portland; FEMI = Federación Médica del Interior. 
no contó con un amplio sustento político, y puso de manifiesto las dificultades políticas de alternativas de reforma, así como el poder político de las instituciones y actores del sector (MSP, 1995). Un cuarto momento lo constituye el proceso de re-dimensionamiento de la ASSE, acompañado de medidas de normatización de la actividad privada en el área, con posterioridad al fracaso de la Ley de Descentralización. Un quinto momento está relacionado con la aplicación del proceso de reforma administrativa del Estado al MSP, donde se consolidan las tendencias del momento anterior. El sexto hito en este proceso está en marcha y se configura a partir de las elecciones nacionales de 1999. La designación de un ministro ajeno al sector salud y la precipitación de la crisis del sub-sistema IAMC han volcado la situación hacia una situación de "crisis explícita", con un fuerte contenido de ajuste auto-regulado por el subsector privado.

El marco de las propuestas actuales, o sea las que permanecen en la agenda, está ubicado en los hitos cuatro, cinco y seis presentados arriba. De este proceso, emergen tres estrategias centrales, que están en discusión, y que corresponden a la lógica de tres agentes colectivos que han emergido como "instituyentes" en este proceso: (a) la tecno-burocracia estatal adscripta al MSP que gestiona la ASSE; (b) la tecno-burocracia adscripta al proyecto de Fortalecimiento Institucional del Sector Salud (FISS), que tiene relación con el MSP, pero con independencia del anterior grupo; y (c) el plenario deIAMC y la FEMI.

- Las propuestas del programa de reforma del Estado

A partir de una política activa generada a nivel del gobierno central, se inicia un nuevo proceso basado en la Ley 16.736 (Uruguay, 1996b) y en el Decreto Reglamentario 186/996 (Uruguay, 1996a). Los objetivos de la Reforma del Estado tienden a: (a) el logro de la mayor eficacia del Estado en su acción normativa, reguladora, de control y de una mayor eficiencia en la prestación de servicios, (b) la redefinición de los objetivos estratégicos, procurando adaptar la modalidad tradicional de la Administración hacia una más gerencial, centrada en los resultados de la gestión pública, cuyo fin último es la satisfacción de las necesi dades de los ciudadanos, (c) la búsqueda de reformulación de las estructuras organizativas, con base a una dirección estratégica, una clara definición de cometidos sustantivos, una descripción de la organización necesaria para cumplir con dicha definición estratégica, y la provisión de los puestos de trabajo requeridos para su funcionamiento con un enfoque gerencial, (d) la modalidad gerencial que privilegia la capacitación y el desempeño eficiente como centro de la política de recursos humanos y la recuperación de las capacidades gerenciales del sector público a través de la alta especialización.

Mediante el Decreto 348/ 997 inciso 12 (Uruguay, 1997) relativo a objetivos estratégicos y cometidos sustantivos del MSP, se mantienen en el Ministerio las tres unidades ejecutoras: Dirección General de Secretaría, Dirección General de la Salud y ASSE. Este proceso, que tiende a la descentralización de la ASSE, todavía se encuentra en desenvolvimiento. Si bien en su origen tendría potencial para promover la integralidad del sistema, ya que fortalece el rol regulador del MSP y dispone cierta autonomía operativa de ASSE; en la práctica, sólo ha generado movimientos de reestructuración pasiva a nivel de la prestación de servicios públicos, vinculados con la mejora de la gestión y la introducción de mecanismos de gerenciamiento y planificación estratégica.

Si bien los gestores de esta reestructuración al interior del MSP utilizan insumos del proyecto FISS, en muchos casos han tomado distancia del mismo, implementando las reformas de los servicios de atención con cierta independencia operativa. Esto lleva a que, en el seno del MSP, se propongan estrategias contradictorias entre sí, al punto que, con la asunción del nuevo ministro, se ha desactivado el proyecto FISS, mientras que se continúa con el otro proceso, que ha perdido sustancialmente su carácter de política activa.

- La propuesta del programa Fortalecimento Institucional del Sector Salud

El conjunto de propuestas más formalizado son los informes generados en el marco del proyecto FISS, financiados por el Banco Mundial, que constituye hasta el presente, un documento central en propuestas de reforma del sistema (FISS, 1997). Según ese documento, la reforma apunta a cuatro objetivos básicos: (1) equidad (de un nivel adecuado de salud entre usuarios con diferentes características); (2) eficiencia microeconómica (costo mínimo adecuado de prestación de servicios a igualdad de servicios); (3) calidad (estándares mínimos para el funcionamiento de todos los prestadores del sistema y un sistema de seguimiento y control); (4) eficiencia en la asignación de recursos (reorientar los recursos en función de niveles de complejidad de servicios y controlar la evo- 
lución de los costos de la atención considerando que la tasa de crecimiento del gasto en salud no podrá mantenerse en el largo plazo). Estos objetivos serían enmarcados en dos alternativas "políticas" de la reforma: una primera, más ambiciosa y, según declara el documento, de mayor impacto sobre la reducción de la tasa de crecimiento del gasto en salud, que es un "modelo global de transformación del sistema actual"; una segunda, menos ambiciosa - pero quizá más viable políticamente -, definida como un conjunto de "ajustes parciales" al sistema.

El modelo global supone la creación de un Fondo Nacional, a partir de los aportes de los presupuestos públicos de salud, los aportes obligatorios al seguro de salud y las contribuciones privadas, que realizaría un pago per capita (que puede ser igual para todos los individuos, o ajustado por franjas de riesgo) a los distintos efectores de salud (instituciones autorizadas que demostraran estar en condiciones de prestar estos servicios, incluyendo en pie de igualdad hospitales públicos, seguros parciales e IAMC), por un canasta de servicios de Asistencia Básica Completa y Obligatoria (ABCO), que eventual mente podría incluir también la cobertura de servicios de alta tecnología brindados actualmente por el FNR, a las personas que eligieran ese prestador de salud. Todo servicio que quede fuera de la canasta se compraría en régimen de libre mercado.

Respecto a los roles del Estado y el mercado, el documento señala que el Estado garantizaría - y subsidiaría - asistencia médica a los indigentes, y los usuarios de los servicios públicos quedarían en libertad de elegir la institución que les provea su canasta de servicios de salud. Con respecto al sistema IAMC actual, el documento afirma que las actuales instituciones podrían actuar como intermediarias, de un modo similar al que hoy actúan las Administradoras de Fondos de Ahorro Previsional (AFAP) en el mercado de fondos de la seguridad social. Obviamente, esto requeriría una agencia central de regulación y financiamiento que fije estándares de servicios, canalice los fondos y controle calidad y resultados.

El modelo de ajustes parciales, por el contrario, supone el mantenimiento del sistema multi-institucional, con un presupuesto público para los organismos públicos y un financiamiento privado y de la seguridad social para las instituciones o efectores privados. Pero se harían ajustes al esquema general. En su conjunto, el paquete de ajustes no parece diferir demasiado del modelo "global".
- La propuesta del plenario de Instituciones de Asistencia M édica Colectiva y de la Federación Médica del Interior

En medio de una gran crisis fiscal, el plenario de IAMC y de la FEMI Ilevó al poder ejecutivo un documento que incluía un diagnóstico sobre la situación del sub-sector y propuestas de salida de la crisis (IAMC/FEMI, 1999). Se plantean como postulados básicos del sub-sistema IAMC Ios valores de la solidaridad, equidad, integralidad, universalidad y libertad de elección del usuario. En función de esto, se propone una serie de medidas que apuntan a mantener los valores constitutivos del sector. Como medidas inmediatas, se propone: (1) recategorización del riesgo crediticio del sector para facilitar y abaratar el acceso de las IAMC al financiamiento bancario; (2) reestructuración de pasivos de corto plazo en deudas de largo plazo para aquellas instituciones que demuestren su capacidad de pago; (3) acordar con los gremios de trabajadores técnicos y no técnicos, en el ámbito del Ministerio de Trabajo y Seguridad Social (MTSS) y con participación del MEF y el MSP, tomar algunas medidas en aquellas instituciones deficitarias y mientras dure tal situación, a los efectos de mantener las fuentes laborales y el nivel de asistencia; (4) cumplimiento por parte del MEF de los controles necesarios sobre los mecanismos de fijación de precios establecidos en el marco normativo vigente, eliminando la competencia ilegal de las instituciones que rebajan unilateralmente las cuotas de los afiliados más jóvenes; (5) extensión de los plazos de aportes regulares personales y patronales al BPS; (6) cumplimiento de los pagos de los plazos contractuales por parte del Estado y de los Gobiernos Municipales por los servicios médicos contratados con las IAMC; (7) extensión a los "seguros parciales" de las mismas condiciones de ingreso y permanencia de los afiliados que rigen para las IAMC.

Como medidas que apuntan a los factores más permanentes, se proponen: (1) adecuación del marco normativo; (2) extensión de la cobertura, vía seguridad social u otros mecanismos, a nuevas capas de la población que mejoren la distribución etaria y permitan abaratar el costo promedio de la atención médica; en esta línea se estaría promoviendo un avance hacia un seguro nacional de salud; (3) adecuación de los convenios laborales; (4) respaldo efectivo a los procesos de reconversión y mejora de la gestión administrativa; (5) adaptación de los mecanismos de regulación de precios; (6) creación de un Centro de Evaluación deTec- 
nologías M édicas, como soporte para la toma de decisiones acerca de las prestaciones que obligatoriamente deben de ser proporcionadas por las IAMC; (7) creación de un programa de garantía de calidad y acreditación de servicios de salud; (8) introducción del médico de familia en la medicina colectiva.

Aproximación a las desigualdades vigentes en el sistema de salud

Un primer paso en el análisis sobre los valores de equidad que pueden emerger de las posibles estrategias de reforma pasa por identificar las desigualdades e inequidades existentes en el modelo actual. En este sentido, como aproximación a la medición de equidad, que aporta información para configurar la situación actual y proyectar posibles impactos, se utilizaron el gasto y la cobertura,.

\section{- El problema del gasto en salud}

En el caso de Uruguay se comprueba el incremento progresivo del gasto en salud, habiendo pasado de $6,5 \%$ del PIB en 1987 a $10 \%$ del PIB en 1995 (Tabla 2), y dicho incremento también se expresa en un aumento del gasto per capita del $243 \%$ (Tabla 2). En función de estos datos, se puede afirmar que las inequidades actuales no están generadas en recortes del gasto, como sucede en otros países. Por el contrario, las propuestas de reforma en Uruguay incluyen el tema del aumento de gasto en sus diagnósticos como problema a intervenir en el corto plazo, toda vez que no se ha conseguido revertir esta tendencia con diversas medidas que se intentaron implementar en diferentes instancias del proceso de reforma.

Pero, si bien las desigualdades no han pasado por el recorte del gasto, sí las podemos encontrar en la distribución del mismo. A pesar de la segmentación del sistema, esas desigualdades involucran fundamentalmente a los dos efectores responsables por la cobertura asistencial de la mayor parte de la población del país: ASSE (sub-sector público) e IAMC (sub-sector privado). En efecto, el análisis de la distribución del gasto entre ambos sub-sectores permite observar que Ias IAMC gastan por beneficiario más del doble (118\% más) de lo que se gasta en el sector público (INE, 1997; SINADI, 1997). Si se toma en cuenta que ambos grupos de beneficiarios deberían recibir la misma canasta de servicios, esta diferencia se constituye en un indicador de desigualdad que debería ser mejor analizado en términos de equidad.
Tabla 2

Datos de población y gasto en salud de Uruguay para el periodo 1987-1995.

\begin{tabular}{ccccc}
\hline Año & $\begin{array}{c}\text { Población } \\
\text { en miles }\end{array}$ & $\begin{array}{c}\text { Gasto en salud } \\
\text { (millones US\$) }\end{array}$ & $\begin{array}{c}\text { Gasto en salud } \\
\text { (\% del PIB) }\end{array}$ & $\begin{array}{c}\text { Gasto en salud } \\
\text { per capita }\end{array}$ \\
\hline 1987 & 2.995 & 482 & 6,5 & 161 \\
1991 & 3.078 & 807 & 8,0 & 261 \\
1992 & 3.098 & 979 & 8,3 & 316 \\
1994 & 3.141 & 1.589 & 9,8 & 506 \\
1995 & 3.162 & 1.745 & 10,0 & 552 \\
\hline
\end{tabular}

Fuente: Fortalecimiento Institucional Sector Salud - Ministerio de Salud Pública (1997).

$\mathrm{PIB}=$ Producto Interior Bruto.

Más allá del hecho de no haber estudios sistemáticos que analicen esta desigualdad en el gasto, en el discurso de los actores relevantes se representa esta desigualdad en términos de inequidad. Esto se transforma en un cuello de botella, ya que las posibles opciones de integralidad del sistema, en el caso de tomar como paradigma el modelo IAMC, implicarían un aumento significativo en el gasto de salud para nivelar hacia arriba. Esta opción de nivelar hacia arriba no asegura automáticamente mejores niveles de equidad, ya que sólo en el caso de aplicación de políticas activas que impliquen la redistribución de recursos en forma desigual, compensando necesidad y posibilidades, se asegurarían resultados consistentes. Por otra parte, la opción de modificar el gasto de las I AMC, tomando como modelo de gasto al sub-sector público, no tendría aceptación por parte de amplios sectores que tienen un fuerte poder de negociación y veto.

Debe tenerse en cuenta que las IAMC ejecutan el $69,5 \%$ del gasto total del sub-sector privado (Tabla 3). Este es un indicador de la fuerza que tienen la empresas de capital social en el sistema. Pero, el restante $30,5 \%$ de ese gasto - proporción que no es menor, si tenemos en cuenta que es un $21,9 \%$ del gasto total en salud - se convierte en una "caja negra" y, como tal, adquiere un lugar privilegiado en la agenda de discusión. Parte de ese porcentaje corresponde al gasto de bolsillo de los usuarios de ambos sectores y, por lo tanto, si aceptamos que es un gasto necesario para corregir en forma individual problemas de cobertura, podemos suponer que, dadas las diferentes capacidades de consumo de los usuarios de diferentes sectores socioeconómicos, el mismo se debe distribuir en forma inequitativa. El gasto de bolsillo mayor está en el rubro farmacia externa, representando el $6,4 \%$ del total del gasto en salud, y su- 
Tabla 3

Estructura institucional del gasto por sub-sector para 1995.

\begin{tabular}{|c|c|c|c|c|}
\hline Sub-sectores & $\begin{array}{l}\text { Gasto en } \\
\text { miles de US\$ }\end{array}$ & $\%$ del gasto & $\begin{array}{l}\text { \% sobre el total } \\
\text { del sector público }\end{array}$ & $\begin{array}{l}\text { \% sobre el total } \\
\text { de acciones a } \\
\text { las personas en } \\
\text { ambos sectores }\end{array}$ \\
\hline Sector público & 509.280 & 28,6 & 100,0 & \\
\hline Acciones a la población & 40.679 & 2,3 & 8,0 & \\
\hline Ministerio de Salud Pública & 31.733 & 1,8 & 6,2 & \\
\hline Comisión honoraria de lucha contra el cáncer & 2.884 & 0,2 & 0,6 & \\
\hline Comisión honoraria por salud cardiovascular & 140 & 0,0 & 0,0 & \\
\hline Comisión honoraria de lucha contra la hidatidosis & 827 & 0,0 & 0,2 & \\
\hline Comisión honoraria de lucha antituberculosa & 5.095 & 0,3 & 1,0 & \\
\hline Acciones a las personas & 468.601 & 26,3 & 92,0 & 100,0 \\
\hline Administración de Servicios de Salud del Estado & 266.726 & 15,0 & 52,4 & 56,9 \\
\hline Dirección Nacional de Sanidad de las Fuerzas Armadas & 33.269 & 1,9 & 6,5 & 7,1 \\
\hline Dirección Nacional de Sanidad Policial & 22.743 & 1,3 & 4,5 & 4,9 \\
\hline Hospital de Clínicas & 28.065 & 1,6 & 5,5 & 6,0 \\
\hline Banco de Previsión Social & 40.167 & 2,3 & 7,9 & 8,6 \\
\hline Banco de Seguros del Estado & 23.755 & 1,3 & 4,7 & 5,1 \\
\hline Empresa Petroquímica del Estado & 9.842 & 0,6 & 1,9 & 2,1 \\
\hline Intendencia Municipal de Montevideo & 7.244 & 0,4 & 1,4 & 1,5 \\
\hline Fondo Nacional de Recursos & 36.141 & 2,0 & 7,1 & 7,7 \\
\hline Administración Nacional de Puertos & 649 & 0,0 & 0,1 & 0,1 \\
\hline Sector privado & 1.272 .012 & 71,4 & & 100,0 \\
\hline Instituciones de Asistencia Médica Colectiva & 883.915 & 49,6 & & 69,5 \\
\hline Fondo Nacional de Recursos & 68.890 & 3,9 & & 5,4 \\
\hline Seguros parciales emergencias móviles & 104.237 & 5,9 & & 8,2 \\
\hline Seguros parciales médicos quirúrgicos & 7.679 & 0,4 & & 0,6 \\
\hline Seguros parciales odontológicos & 44.868 & 2,5 & & 3,5 \\
\hline Farmacias externas & 114.703 & 6,4 & & 9,0 \\
\hline Casas de salud y residenciales & 6.434 & 0,4 & & 0,5 \\
\hline Caja notarial & 6.359 & 0,4 & & 0,5 \\
\hline Asistencia estrictamente privada & 34.927 & 2,0 & & 2,7 \\
\hline Total del gasto & 1.781 .293 & 100,0 & & \\
\hline
\end{tabular}

Fuente: Fortalecimiento Institucional Sector Salud - Ministerio de Salud Pública (1999).

perando al gasto en alta tecnología implementado a través del FNR (5,9\%). Si tomamos en cuenta que el sub-sector público proporciona medicamentos a sus usuarios y el sub-sistema IAMC vende los medicamentos en la farmacia interna a precios subsidiados, ese gasto de bolsillo es un indicador de insuficiencia de cobertura y, por lo tanto, de desigualdad.

Otro rubro importante es el seguro parcial de emergencias móviles, que brindan cobertura en urgencias y emergencias ambulatorias por un sistema de pre-pago. Este sistema es utilizado y pagado en forma voluntaria por usuarios de ambos sectores como una estrategia pa- ra compensar deficiencias en la cobertura formal de atención primaria. El costo es de 9 dólares por mes, y cubren atención de emergencias en vía pública y domicilio con traslado en unidades coronarias móviles, y servicios de urgencia domiciliaria. Representa el 5,9\% del gasto en salud, la misma cantidad que consumen los tratamientos de medicina altamente especializada para todo el sistema. Este rubro capta parte de la capacidad de pago de los usuarios del sub-sector público, con un efecto regresivo, ya que colabora con el financiamiento del uso de los mismos por parte de los usuarios del sub-sector privado, en condiciones claramente 
desiguales. En la medida que ese seguro cobra a todos los asegurados una misma cuota, y teniendo en cuenta que los ingresos de los usuarios de las IAMC son significativamente mayores que los usuarios del MSP, el porcentaje de la cuota sobre los ingresos implica una relación inequitativa, ya que no se cobra de acuerdo a las posibilidades. Por otra parte, en el caso de los usuarios de las I AMC, las prestaciones de ese seguro parcial ya están cubiertas dentro de la canasta básica de las propias I AMC. Lo que se gana al estar asegurado es mayor rapidez en la atención. En el caso de los usuarios del MSPASSE, la atención de urgencia y emergencia es ampliamente deficitaria, por lo que el servicio dado por el seguro significa un plus en cantidad y talvez en calidad. Esta situación Ileva a que parte de los usuarios del MSP-ASSE apliquen su limitada capacidad de pago a estos servicios, que, por definición, sólo resuelven las situaciones coyunturales más críticas, ya que no cubren atención con especialistas, internación, operaciones quirúrgicas, uso de tecnología diagnóstica, entre otras prestaciones.

La relación entre ingresos y gasto en salud de las familias puede proporcionar también una aproximación a la evaluación de la equidad en el sistema. Los datos permiten observar que, tanto en Montevideo como en el Interior, los niveles más bajos de gastos en salud se localizan en los deciles de menores y mayores ingresos de los hogares (Tabla 4).

Los valores de los deciles más bajos indican un déficit de consumo por imposibilidad económica de acceso. En general son usuarios del MSP en forma gratuita, y los gastos se concentran en algunos casos en Emergencias Móviles o gasto de bolsillo en medicamentos.

Los valores de los deciles más altos pueden suponer un efecto regresivo del gasto, ya que las características del sub-sistema I AMC, fuertemente extendido, subsidiado y regulado por el Ministerio de Economía y Finanzas, abarata, en términos relativos, el costo de la cuota de la canasta básica. Los dos seguros más extendidos son el correspondiente a las IAMC y el correspondiente a las Emergencias Móviles. En ambos casos, la cuota es fija, no se contemplándo el pago proporcional a los ingresos. Por otra parte, el acceso a la alta tecnología está cubierto dentro de la cuota de las IAMC. Esto implica que, para los altos ingresos, el costo de acceso al paquete de servicios disponibles a nivel colectivo va a ser proporcionalmente menor que para los ingresos medios y bajos.

Una discusión aparte merece el gasto en medicina altamente especializada, canalizado a través del FNR. Este fondo cubre, desde la dé-

\begin{tabular}{lcc} 
Tabla 4 \\
\hline \\
Análisis del gasto en salud de las familias en relación al ingreso de las familias \\
expandido (gasto en salud/ingreso). & & \\
\multicolumn{4}{l}{ Montevideo (\%) } & Interior (\%) \\
\hline Total & 9,6 & 8,5 \\
Decil 1 & 9,1 & 4,4 \\
Decil 2 & 11,0 & 9,4 \\
Decil 3 & 11,9 & 8,9 \\
Decil 4 & 12,2 & 12,5 \\
Decil 5 & 12,7 & 10,4 \\
Decil 6 & 11,5 & 8,7 \\
Decil 7 & 10,9 & 10,3 \\
Decil 8 & 10,8 & 10,0 \\
Decil 9 & 8,6 & 7,4 \\
Decil 10 & 5,8 & 5,6 \\
\hline
\end{tabular}

Fuente: Instituto Nacional de Estadística (1997).

cada del 80, las intervenciones de un paquete de medicina de alta tecnología para la totalidad de usuarios del sistema de salud. Es el único caso del sistema donde hay un tercer pagador (el FNR); el financiamiento se cubre a través de un porcentaje de la cuota social del subsector privado (3,9\% del gasto total en salud) y de un pago por usuario del sub-sector público ( $2 \%$ del gasto total en salud). Los efectores de estos servicios son las Instituciones de Medicina Altamente Especializada (IMAES) que son habilitadas por el FNR para realizar estas prestaciones.

El derecho a la cobertura del FNR es universal, bastando con la aprobación del diagnóstico médico de un servicio del FNR para que la atención se haga efectiva. Sin embargo, en esta práctica es donde se registran las desigualdades más claras ( Tabla 5). Si se toma en cuenta el conjunto de las técnicas de medicina altamente especializada que forman parte de la cobertura del FNR, puede observarse que se gasta en promedio, por cada beneficiario del sistema IAMC, un 37,6\% más de lo que se gasta en los beneficiarios del MSP. Esta desigualdad no puede ser atribuida a un diferente perfil epidemiológico, salvo en el caso de grandes quemados, los cuales se registran con mayor frecuencia en los niveles socioeconómicos más bajos, al estar asociados a acci dentes domésticos en viviendas precarias y a accidentes en plantas industriales. En los casos restantes, es probable que la falta de información del usuario con relación a los derechos que implica esta cobertura - y la barrera sociocultural existente para gestionarla -, sumada a aspectos relacio- 
nados con la relación médico-paciente en el sector público, conspiren contra la posibilidad de que esta cobertura se haga efectiva.

Equidad en la cobertura

del sistema de salud

En función de los datos disponibles, el clivaje que se muestra más fecundo para examinar los problemas de equidad está asociado a la cobertura asistencial. Si tomamos la variable geográfica, Montevideo y el Interior del país presentan formas altamente diferenciadas de organización de la cobertura. En Montevideo, se ha desarrollado el sub-sistema IAMC más tempranamente y con mayor cobertura que en el interior del país. La cobertura de la seguridad social, a su vez, vinculada a las categorías profesionales formales, se desarrolló básicamente también en Montevideo, incluyéndose los trabajadores rurales, de la construcción y de los servicios domésticos (éste con fuerte impacto en el interior) a partir de 1984. Por otro lado, al realizarse un análisis de correlación simple, con otros factores estructurales de inequidad (IDH, PIB per capita y PIB total), según la matriz de correlación planteada (Tabla 6), surgen correlaciones significativas. La relación entre tasa de cobertura e IDH es significativa al 0,01, lo que indica una fuerte correlación entre ambas variables: a mayor IDH, mayor cobertura I AMC. Los valores se concentran en torno a la recta de regresión, salvo en el caso de Montevideo, que, dadas sus características específicas, debe de considerarse como un caso desviado. Lo mismo se observa en relación al PIB per capita: a la mayor tasa de cobertura IAMC corresponde el mayor PIB per capita, siendo válidas las mismas consideraciones para Montevideo, y la relación es altamente significativa. En el caso de precariedad del empleo, con menor correlación (significativa al 0,05), encontramos una relación negativa: a mayor precariedad, menor cobertura IAMC. En este caso, Montevideo se separa claramente del otro grupo de departamentos.

Hasta aquí, hemos tomado la cobertura a nivel general. Entretanto, explorando las variables individuales de los beneficiarios - edad, condiciones de actividad, y nivel de instrucción - se evidencian inequidades en la cobertura relacionadas con los diferentes grupos sociales.

La cobertura varía según los diferentes grupos etarios. Si asumimos la hipótesis de que los individuos sin cobertura tienen formalmente la cobertura del MSP pero no la han utilizado hasta la fecha del censo, resulta consistente la distribución de esta categoría, donde, a mayor edad, baja el porcentaje de no cubiertos. Esta cobertura formal no efectivizada encubre una de las inequidades del sistema, pues no logra captar para controles periódicos preventivos a porcentajes muy importantes de la población. En el caso de la relación IAMC-MSP, la primera presenta una baja cobertura a los grupos menores de 15 años, pero se equilibra en el grupo de 15 a 49, ya que aparte de la afiliación individual, opera el seguro de la seguridad social, que cubre sólo al trabajador (no a su familia). En los grupos de mayor edad, aumenta la proporción de cobertura IAMC. Esto se debe a dos factores: (a) las estrategias privadas, individuales y familiares, de asegurar la cobertura I AM C en la edad de mayor riesgo; y (b) la reciente inclusión de los jubilados de menores ingresos en el seguro de la seguridad social. Los diferentes diagnósticos sobre la crisis del sistema apuntan a responsabilizar a estas estrategias, entre otros factores, por el desfinanciamiento del sector, ya que atentan contra el principio de solidaridad intergeneracional.

Cuando tomamos en consideración la condición de actividad del individuo, correlacionándola con el nivel de cobertura alcanzado, aparece claramente la relación existente entre cobertura y condición de actividad, mostrando un gran peso el clivaje Montevideo-Interior. En el caso de menores de 14 años, las diferencias entre afiliación individual a una IAMC y cobertura del MSP es altamente significativa y refuerza los expresado sobre inequidades estructurales (INE, 1997).

El nivel de instrucción muestra también un alto efecto discriminador. La cobertura IAMC crece con el nivel educativo y la cobertura MSP baja con el nivel educativo. Esta relación también se da (pero más atenuada) si tomamos el clivaje Montevideo-Interior. En el caso del interior, intervienen otras variables ya analizadas que especifican la relación, aumentando la participación del MSP en la cobertura (INE, 1997).

Por último, la variable ingresos, que está fuertemente vinculada a las anteriores, confirma la relación ya planteada: a mayores ingresos, mayor cobertura IAMC, y a menor ingreso, mayor cobertura MSP (INE, 1997).

Con relación a la estructura de la población afiliada a las IAMC, queda clara la importancia del componente de afiliados por la seguridad social en el total de afiliados de las IAMC, básicamente entre los 20 y los 59 años (INE, 1997). Este es un mecanismo crucial para el financiamiento del sub-sistema, ya que es una población cautiva del mismo (el seguro no es opcional). Parte de las estrategias de reforma planteadas desde este sector pasan por integrar a 
Diferencias en el acceso a la alta tecnología financiada por el Fondo $\mathrm{N}$ acional de Recursos, entre los beneficiarios del MSP y de las IAMC, medida a través del gasto en pesos uruguayos de 1997.

\begin{tabular}{|c|c|c|c|c|c|c|c|c|c|}
\hline \multirow[t]{2}{*}{ Tecnologías } & \multicolumn{3}{|c|}{ Actos } & \multirow{2}{*}{$\begin{array}{l}\text { Gasto } \\
\text { Total }\end{array}$} & \multicolumn{2}{|c|}{ Gasto beneficiarios } & \multirow{2}{*}{$\begin{array}{l}\text { Gasto } \\
\text { IAMC }\end{array}$} & \multirow{2}{*}{$\begin{array}{l}\text { Gasto } \\
\text { M SP }\end{array}$} & \multirow{2}{*}{$\begin{array}{l}\text { IAMC/ } \\
\text { MSP }\end{array}$} \\
\hline & IAMC & MSP & Total & & IAMC & MSP & & & \\
\hline Dialisis & 155.300 & 107.270 & 262.570 & 355.501 .177 & 210.265 .197 & 145.235 .980 & 135,1 & 141,5 & 0,95 \\
\hline Dialisis peritoneal c.a. & 523 & 404 & 927 & 27.113 .510 & 15.297 .050 & 11.816 .460 & 9,8 & 11,5 & 0,85 \\
\hline Transplantes renales & 15 & 17 & 32 & 15.109 .266 & 7.082 .468 & 8.026 .798 & 4,6 & 7,8 & 0,58 \\
\hline Quemados & 27 & 111 & 138 & 46.534 .046 & 9.104 .487 & 37.429 .559 & 5,9 & 36,5 & 0,16 \\
\hline Marcapasos & 1.212 & 423 & 1.635 & 60.584 .104 & 44.910 .051 & 15.674 .053 & 28,9 & 15,3 & 1,90 \\
\hline Litotricias & 1.811 & 359 & 2.170 & 43.397 .220 & 36.217 .680 & 7.179 .540 & 23,3 & 7,0 & 3,33 \\
\hline Protesis de rodilla & 381 & 75 & 456 & 20.226 .843 & 16.900 .060 & 3.326 .783 & 10,9 & 3,2 & 3,35 \\
\hline Protesis de cadera & 1.609 & 552 & 2.161 & 66.728 .634 & 49.683 .652 & 17.044 .982 & 31,9 & 16,6 & 1,92 \\
\hline Transplantes medula osea & 54 & 20 & 74 & 43.753 .813 & 31.928 .458 & 11.825 .355 & 20,5 & 11,5 & 1,78 \\
\hline Hemodinamias & 4.719 & 1.711 & 6.430 & 60.854 .889 & 44.661 .621 & 16.193 .268 & 28,7 & 15,8 & 1,82 \\
\hline Angioplastias & 1.330 & 347 & 1.677 & 120.103 .273 & 95.251 .850 & 24.851 .423 & 61,2 & 24,2 & 2,53 \\
\hline Cirugías cardiacas & 1.725 & 652 & 2.377 & 373.746 .673 & 271.229 .706 & 102.516 .967 & 174,3 & 99,9 & 1,74 \\
\hline Cardiodesfibriladores & 25 & 6 & 31 & 11.530 .061 & 9.298 .436 & 2.231 .625 & 6,0 & 2,2 & 2,75 \\
\hline Totales & & & & 1.245 .183 .509 & 841.830 .718 & 403.352 .791 & 541,0 & 393,0 & \\
\hline
\end{tabular}

Fuente: Fondo Nacional de Recursos (1997).

MSP = Ministerio de Salud Pública; IAMC = Instituciones de Asistencia Médica Colectiva.

Tabla 6

Matriz de correlación entre la variable dependiente tasa de cobertura IAMC y variables independientes relacionadas con desigualdades estructurales a nivel global.

\begin{tabular}{|c|c|c|c|c|c|c|c|c|}
\hline \multirow[t]{2}{*}{ Tasa IAMC } & \multicolumn{2}{|l|}{ Tasa IAMC } & \multicolumn{2}{|c|}{ Empleo precario } & \multicolumn{2}{|l|}{ IDH } & \multicolumn{2}{|c|}{ PIB per capita } \\
\hline & r de Pearson & $\mathrm{n}$ & r de Person & $n$ & $r$ de Person & $\mathrm{n}$ & rde Person & $\mathrm{n}$ \\
\hline Empleo precario & $-0,466^{*}$ & 19 & & & & & & \\
\hline IDH & $0,682 * *$ & 19 & $-0,446$ & 19 & & & & \\
\hline PIB per capita & $0,700 * *$ & 19 & $-0,422$ & 19 & $0,714 * *$ & 19 & & \\
\hline PIB Total & $0,805^{* *}$ & 19 & $-0,340$ & 19 & 0,384 & 19 & $0,713^{* *}$ & 19 \\
\hline
\end{tabular}

IAMC = Instituciones de Asistencia Médica Colectiva; IDH = Índice de Desarrollo Humano;

$\mathrm{PIB}=$ Producto Interior Bruto.

*Correlación significativa al nivel del 0,05

** Correlación significativa al nivel del 0,01.

este mecanismo de seguro a los grupos no cubiertos en dos sentidos: (a) los grupos menores de 20 y mayores de 60; y (b) los familiares de los grupos de edad ya cubiertos.

\section{Discusión}

Entre algunos de los problemas que enfrenta hoy el sector salud en Uruguay, el aumento del gasto público y privado en salud, la pérdida progresiva de rentabilidad del sistema IAMC (además de las crisis financieras asociadas) y la inequidad, la ineficiencia y las dificultades de regulación del sistema han estado en el centro de los diagnósticos que reclaman por una política coherente de reforma del sistema en su conjunto. La evolución de la rentabilidad de las IAMC ha sido negativa en los últimos años: mientras el valor promedio 1983-1990 estuvo en $2 \%$ en todo el país y en 1,7\% en Montevideo, en el período 1991-1998, la rentabilidad fue de - $0,45 \%$ en todo el país y de - $0,7 \%$ en Montevideo (Brecha, 1999). 
En primer lugar, los datos disponibles informan un crecimiento del gasto sanitario, y la tasa de crecimiento se considera insostenible en el corto y mediano plazo. La "contención del gasto" en salud se ha transformado en uno de los principios clave para juzgar la virtud relativa de distintas medidas de reforma.

En segundo lugar, la crisis de algunas instituciones del sistema IAMC (que llevó en marzo del 2000 a la demanda de las instituciones del sector por aumento de la cuota de pre-pago y a la respuesta negativa del gobierno a estas demandas como parte de su estrategia de contención del gasto), si llega a ser generalizada, en un contexto de rentabilidad negativa y sostenida de las mismas, afectaría al sistema en su conjunto. En este sentido, debe tenerse en cuenta que el $47 \%$ de la atención (y la totalidad de la cobertura del seguro de la seguridad social) es prestado por las IAMC. Asimismo, la extensión de la cobertura a través de modalidades del seguro social ha seguido una tendencia creciente en dirección de la consolidación del modelo IAMC.

En tercer lugar, hoy se verifican problemas de inequidad sostenida en el acceso y en la cobertura de la población a los servicios de salud, básicamente entre el sistema público y el privado (ASSE vs. IAMC) y entre regiones (Montevideo e Interior). El sistema IAMC, conformado por instituciones privadas, con fuerte control estatal, el cual incluye el seguro de la seguridad social, destina 568 dólares por año por cada afiliado, mientras que ASSE destina por año 259 dólares. Esta situación, donde el sistema IAMC gasta más que el doble del sector público, es un indicador fuerte de desigualdad, agravado por los niveles de riesgo diferenciales para ambas poblaciones.

En cuanto a los indicadores de cobertura, la primera variable que surge como relevante es la desigualdad geográfica. Uruguay presenta un desarrollo desigual entre diferentes unidades territoriales, por lo que se presupone que esto puede ser extensivo al problema concreto de la cobertura de salud. Se muestran diferencias significativas entre Montevideo y el Interior del país, en la relación entre la cobertura IAMC y la cobertura MSP. Si medimos la relación entre cobertura IAM C-M SP y otras variables que se consideran aproximaciones a una medición de equidad en términos más generales, encontramos grados de correlación significativos entre niveles de desarrollo y cobertura de las IAMC y una relación inversa entre precariedad de empleo y cobertura IAMC. Esto indica un patrón de desigualdad estructural en el sistema de salud.
El menú de variables utilizadas para establecer correlaciones que expliquen los diferenciales de cobertura - edad, actividad y nivel educativo - indica que ésta está vinculada al nivel socioeconómico de los usuarios: los que tienen mejores salarios, mejor educación, están en una franja de edad donde pueden ser económicamente activos y efectivamente lo son, tienen acceso a la cobertura IAMC. Los sectores que quedan fuera de esta cobertura, menores de 15 años y mayores de 60, y/ o con precariedad en el empleo, constituyen un paquete de usuarios fuertemente disputados por el sector IAMC, que sólo podrían acceder al sub-sistema con una fuerte subvención estatal y/ o políticas activas redistributivas.

En cuarto lugar, deben contarse los aspectos relativos a la regulación y la coordinación institucional, que afectan la eficiencia total del sistema. Aspectos tales como la superposición de servicios basada en la descoordinación interinstitucional, así como la falta de mecanismos de regulación y evaluación, parecen cuestionar fuertemente el carácter integral del sistema de salud, lo que genera impactos sobre la calidad y los costos de la atención.

\section{Conclusiones}

El proceso de reforma del sistema de servicios de salud en Uruguay ha devenido una situación en la cual la fuerte estructuración de un sistema altamente fragmentado conspira contra opciones de políticas activas en el sector. Las opciones con mayores probabilidades de viabilidad son de reestructuración pasiva. En ambos casos, no se registra la prevalencia de un paradigma que prioriza un modelo de protección social sobre otro, por lo contrario, existe la tendencia de profundización del carácter mixto del mismo.

Las inequidades registradas en la situación actual, básicamente concentradas en el gasto y en la cobertura entre sub-sectores y a nivel territorial, tienden a agravarse con las propuestas planteadas, ya que en las mismas no se contemplan mecanismos redistributivos, ni aumento en el gasto global en salud. La única redistribución planteada es regresiva para sectores de ingresos medios, cuya capacidad de veto es una limitante seria a su implementación.

Las medidas emergentes del actual proceso se sustentan en una estrategia de reestructuración pasiva que intenta aplicar la Reforma Administrativa del Estado al sub-sector público, como mecanismo de mejora de la gestión con un correlato de contención de costos. Para el 
sector IAMC, prevé una política de administración de la crisis, focalizando apoyos y/ o subvenciones en las instituciones que se acrediten como viables y acepten ajustar su funcionamiento a parámetros que aseguren la contención del déficit. Esto puede implicar aumento de cobertura por parte del sub-sistema I AMC, mediante extensión del seguro de la seguridad social, pero no incluye políticas de tipo redistributivo que modifiquen los actuales valores de equidad.

El proceso iniciado en el último período de gobierno (1995-2000), bajo el Partido Colorado, a través de las acciones de un nuevo Ministerio, ha significado un alejamiento sostenido de propuestas de reforma tendientes a generar un sistema de salud integrado, generando hechos concretos que debilitan las perspectivas de diseño de políticas activas en el sector. Como elemento significativo encontramos la desarticulación parcial del proyecto FISS, desde donde se estaban planteando las estrategias de políticas activas. Todo indica que se ha tomado la opción por una reestructuración pasiva. Esto implica, en términos generales, una administración de la crisis en el sub-sector público, y un agravamiento de la crisis en el sector privado colectivo. Esto ha provocado el cierre y la fusión de instituciones, el aumento de cuotas y un ambiente de conflicto generalizado entre los diferentes actores corporativos integrantes del sector salud.
El actual gobierno que asumió el poder en marzo de 2000 , teniendo como presidente a Jorge Batlle del sector liberal del partido Colorado, ha retirado de la agenda de reformas al sector salud. Luego de la experiencia frustrada del ministro Solari en el anterior período de gobierno, quedó demostrado el fuerte costo político que tiene en Uruguay la implementación de un proceso de reforma en esta área. Luego del cambio de gobierno, existían dos opciones, volver sobre la propuesta de reforma aprovechando la legitimidad emergente del proceso electoral o mantener un perfil bajo en esta área, apostando a la reestructuración pasiva. Se ha optado por la segunda, instalando ministros (ya han pasado dos ministros en dos años) con un fuerte perfil empresarial, sin antecedentes que los vinculen con las diferentes propuestas de reformas existentes en la agenda.

El inexistente perfil reformista de esos ministros ha dado a sus respectivas gestiones una impronta basicamente administrativa, que, en el corto plazo, no permite acciones vinculadas. Pero, en la medida en que la crisis del sub-sector IAMC ha superado las estimaciones que se podían realizar a principios de este período de gobierno, se puede suponer que, de no mediar un cambio en el accionar ministerial, los resultados al final del período agravarían la crisis, ya que la viabilidad política de las medidas actuales no está asegurada, pues éstas podrían afectar sustancialmente al modelo de Welfare State y generar nuevas coaliciones de veto.

\section{Agradecimentos}

Este proyecto fue desarrollado en el Centro de Informaciones y Estudios del Uruguay, como parte del Programa Equity-oriented Health Policy Analysis in Latin America, implementado por la Red de Investigación en Sistemas y Servicios de Salud en el Cono Sur de América Latina, financiado por el Internacional Development Research Center - IDRC, de Canadá. Agradecemos el soporte técnico de Celia Almeida, Coordinadores del Programa, y Secretaria Ejecutiva de la Red, y el asesoramiento de los economistas Luis Lasarov y Carlos Grau, en la elaboración de información sobre financiamento, cobertura y gastos. 


\section{Referencias}

BRECHA, 1999: Liquidar al Mutualismo para Resolver su Crisis. Montevideo: Editora Brecha.

BRESSER, C.; MARAVALL, M. \& PRZEWORSKI, A., 1993. Reformas econômicas em democracias recentes: Uma abordagem social-democrata. Dados, 36:1-84.

CELADE (Centro Latinoamericano de Demografía)/ FNUAP (Fondo de Población de las Naciones Unidas)/ MSP (Ministerio de Salud Pública)/ OPS (Organización Panamericana de la Salud), 1994. Mujer y Fecundidad en Uruguay: Factores Determinantes Directos de la Fecundidad y sus Implicancias en Salud. Montevideo: Editora Trilce.

CEPAL (Comisión Económica para América Latina y el Caribe), 1997. Panorama Social de América Latina, 1996. Santiago de Chile: CEPAL.

FILGUEIRA, F.; MORAES, J.; MOREIRA C.; FERNANDEZ, J. \& FILGUEIRA, C., 1999. Political Environments, Sector Specific Configurations and Strategic Devices: Understanding Institutional Reform in Uruguay. Working Paper R-351. Washington, DC: Inter-American Development Bank/ Office of the Chief Economist/Latin American Research Network.

FISS (Fortalecimiento Institucional del Sector Salud), 1997. Análisis sobre alternativas de regulación y financiamiento del Sector Salud: Sus impactos sobre los objetivos de la reforma y los principales actores del sector. Documento Actividad 1, Subcomponente 2, Componente 2o Montevideo: FISS.

IAMC (Instituciones de Asistencia Médica Colectiva)/ FEMI (Federación M édica del Interior), 1999. Situación de las Instituciones de Asi stencia Médica Colectiva y Propuesta de Soluciones. Montevideo: IAMC/FEMI.

INE (Instituto Nacional de Estadística), 1963. Censo Nacional. Montevideo: INE.

INE (Instituto Nacional de Estadística), 1985. Censo Nacional. Montevideo: INE.

INE (Instituto Nacional de Estadística), 1996. Censo Nacional. Montevideo: INE.

INE (Instituto Nacional de Estadística), 1997. Encuesta de Hogares. Montevideo: INE.

MIDAGLIA, C., 1998. ¿Vieja o Nueva Institucionalidad? Las Políticas Sociales en el Uruguay de los 90'. Tese de Doutorado. Rio de Janeiro: Instituto Universitário de Pesquisas do Rio de Janeiro.

MOREIRA, C. \& FERNANDEZ, J., 1997. Políticas de Ajuste en el Sistema Público de Salud: Una Visión desde los Agentes. Documento de Trabajo 202. Montevideo: Centro de Informaciones y Estudios del Uruguay/Organización Panamericana de la Salud/Consejo Latino Americano de Ciencias Sociales.
MORLEY, S.; MACHADO, R. \& PETTINATO, S., 1999. Indexes of Estructural Reform in Latin America, Serie Reformas Económicas 12. Santiago de Chile: Comisión Económica para América Latina y el Caribe.

M SP (Ministerio de Salud Pública), 1995. Programa deAcción dela Administración de los Servicios de Salud del Estado. Programa Oficial: 1995-1999. Montevideo: Administración de Servicios de Salud del Estado, Ministerio de Salud Pública.

NELSON, J., 1992. Poverty, equity and politics of adjustment. In: The Politics of Economy Adjustment. International Constraints, Distributive Conflicts and the State (S. Haggard \& R. Kaufman, ed.), pp. 221-270, New Jersey: Princeton University Press.

PIOTTI, D., 1995. La Dimensión Centralización - Descentralización en el Proceso de Reforma Sanitaria del Uruguay 1985-1995. Montevideo: Organización Panamericana de la Salud.

PNUD (Programa de las Naciones Unidas para el Desarrollo), 1999. Desarrollo Humano en el Uruguay. Montevideo: PNUD.

SINADI (Sistema Nacional de Información), 1997. Datos Sobre Información Contable, EconómicoFinanciera, de Cobertura y deUtilización del SubSector IAMC. Montevideo: SINADI, Ministerio de Salud Publica.

URU GUAY, 1996a. Decreto 186/ 996 del 16 de mayo de 1996. Reglamento de la ley 16736 en lo concerniente a la reforma de estructuras organizativas de los incisos del presupuesto nacional. Montevideo: Diario Oficial dela República Oriental del Uruguay, no 24537, p. 378-A, 28 mayo.

URUGUAY, 1996b. Ley 16736 del 5 enero de 1996. Ley de Presupuesto. Montevideo: Diario Oficial dela República Oriental del Uruguay, no 24257, p 774, 12 enero.

URUGUAY, 1997. Decreto 348/ 997 del 19 de setiembre de 1997. Reglamento de la ley 16736 en lo concerniente a la reforma de estructuras organizativas del Ministerio de Salud Pública. Montevideo: Diario Oficial dela República Oriental de Uruguay, no 24883, p. 29-A, 7 octubre.

WHITEHEAD, M., 1992. The concepts and principles of equity in health. International Journal of Health Services, 22:429-445.

Recebido el 27 de junio de 2001

Versión final presentada el 17 de octubre de 2001

Aprobado el 4 de diciembre de 2001 